\title{
Educational fiber optic transmission equipment with dedicated BER features
}

Pedro Vizcaya-Guarin, Juan Alvarez, Juan Luna, Angela Guzman, Hypolito Kalinowski

Pedro R. Vizcaya-Guarin, Juan Carlos Alvarez, Juan Carlos Luna, Angela Maria Guzman, Hypolito Jose Kalinowski, "Educational fiber optic transmission equipment with dedicated BER features," Proc. SPIE 1603, Education in Optics, (1 March 1992); doi: 10.1117/12.57888 
Educational fiber optic transmission equipment

with dedicated B. E. R. features

\author{
Pedro R. Vizcaya-Guarín \\ Juan Carlos Alvarez, \\ Juan Carlos Luna.
}

Pontificia Universidad Javeriana,

Facultad de Ingenieria.

Departamento de Electrónica

A. A. 21522 Bogotá-Colombia.

Ange la María Guzmán

Universidad Nacional de Colombia,

Facultad de Ciencias,

Departamento de Física

Bogotá, Colombia.

Hypol i to Josć Kal inowski

Ccntro Fedcral de Educação Tecnológica do Paraná,

Áv. Sete de Setembro, 3165

80230 Curitiba(PR), Brazil.

\begin{abstract}
We designed a low cost optical transmission system for use in undergraduate courses in physics and engineering. The system includes boards for bit crror rate (BER) measurements, digital and analog transmitters and receivers, master clock, pseudo-random sequence, and noise generators. Programmable logic components were used for both, the BER meter and the pseudorandom sequence generator. The cost. of the equipment and its design simplicity makes it suitable for most teaching laboratories.
\end{abstract}

\title{
1. INTRODUCTION
}

The fast development of optical communications requires extra training of students in telecommunications or electronic engineering or even in physics. Some topics that should be taught to students of related technologies are optcelectronics, fiber properties, and system performance. is fiber optic communication systems are mainly digital, one of the main characterization procedures adopted is the measurement of the BER. Hovever, this measurement usually requires a dedicated BER test set, which costs several thousand dollars. This figure is almost prohibitive for teaching purposes in developing countries.

There are some educational equipment companies that sell optical 
transmission systems usually with data rates up to $10 \mathrm{Mbit} / \mathrm{s}^{1,2}$. This equipment uses light emitting diodes (LED) as optical source, due to their low cost and the simplicity of their electronic driving circuit. These systems are normaly designed for use with plastic clad silica fibers, or even all plastic ones. This fact usually reduces the length of the optical link to some tens or hundreds of meters. Even if they are useful to train students on how to assemble a transmitter-receiver pair and to acquaint them with the work with non visible optical propagation, those systems still require the use of a BER test set for receiver sensitivity determination.

Another idea was presented by people from the Eldegenossige Technische Hochschulc (ETH - Zurich). Thcy introduccd a scmiconductor lascr as optical source, taking advantage from the low cost of lasers for compact disk players. Their system has far better performance than that mentioned previously and allows the nse of normal telecommunication fibers, connectors and splices in the optical link. One advantage of using a laser as an optical source is the possibility of laser characterization measurements like optical power vs. current, temperature effects, spectral output as a function of current and so on. However, this system also requires the BER test set for system performance measurements.

We designed our system basically to overcome the necessity of a BER test set. In this way it is affordable for teaching laboratories in developing countries. The basic system components are described in the next sections. Even recognizing that better experimental work may be conducted by a laser bascd systcm likc thc onc from ETH, we uscd IRED (infrarcd cmittcr diodcs) as optical sources because LED lasers are not readily available in our countries. Without the metallic enclosure and power suply, our system costs a.bout. IIS $\$ 400$, a reasonable amount, for a school budget.

We also included an analog subsystem in order to allow experiments using wideband transmission over optical fibers. This will help students to be more acquainted with analog transmission over optical fibers and the signal distorsion involved.

\section{GENERAL OVERVIEW}

A block diagram of the system is shown in Figure 1. The optic fiber based communication system has two baseband modules, one for analog transmission and the other for digital transmission. Several modules were built to evaluate the performance of the digital link: three test signal gencrator modulcs (a mastcr clock, a pscudo-random scquence gencrator, and a noise generator) and a BER meter. These modules may be used independently as signal test generators or BER meter for general digital transmission evaluation. Fach one of these modules will be briefly described bellow. 


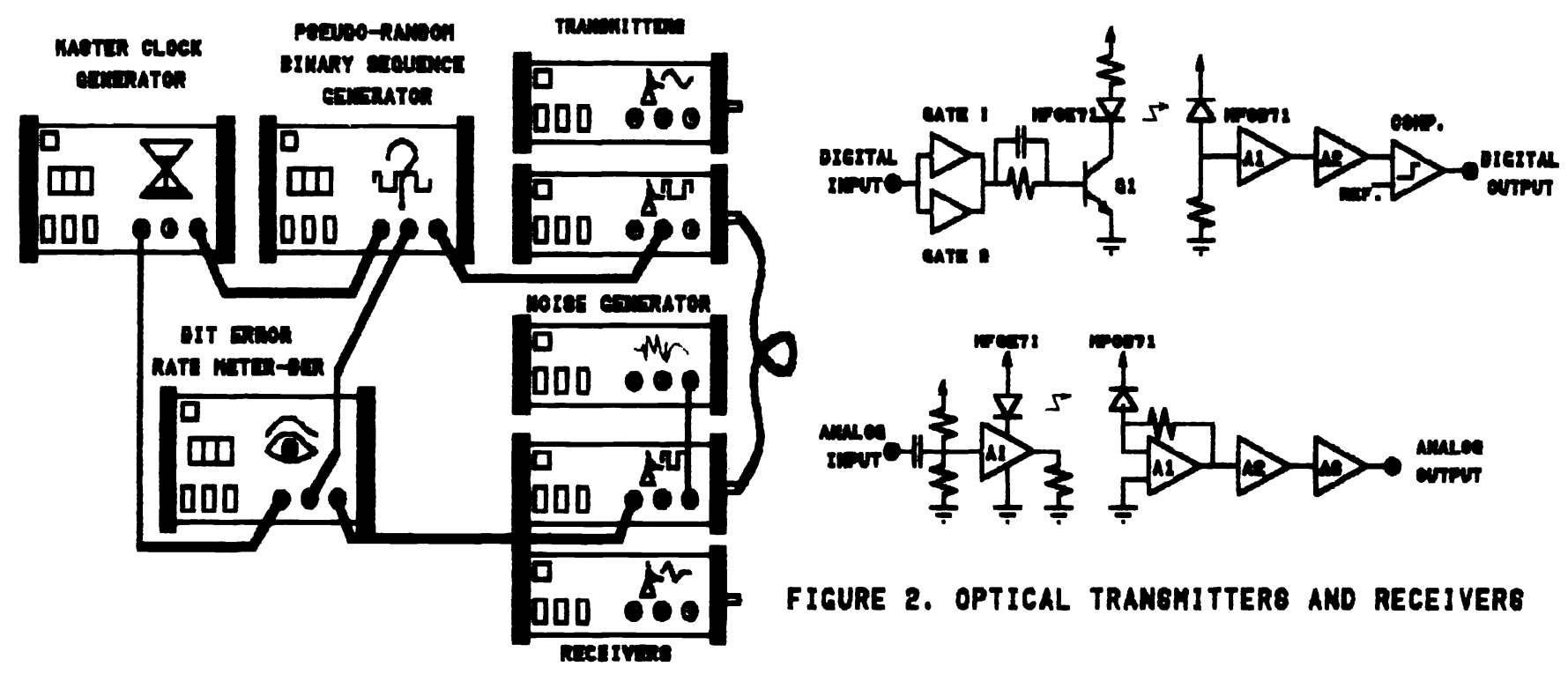

FIGURE 1. GENERAL BLOCK DIAGRAM
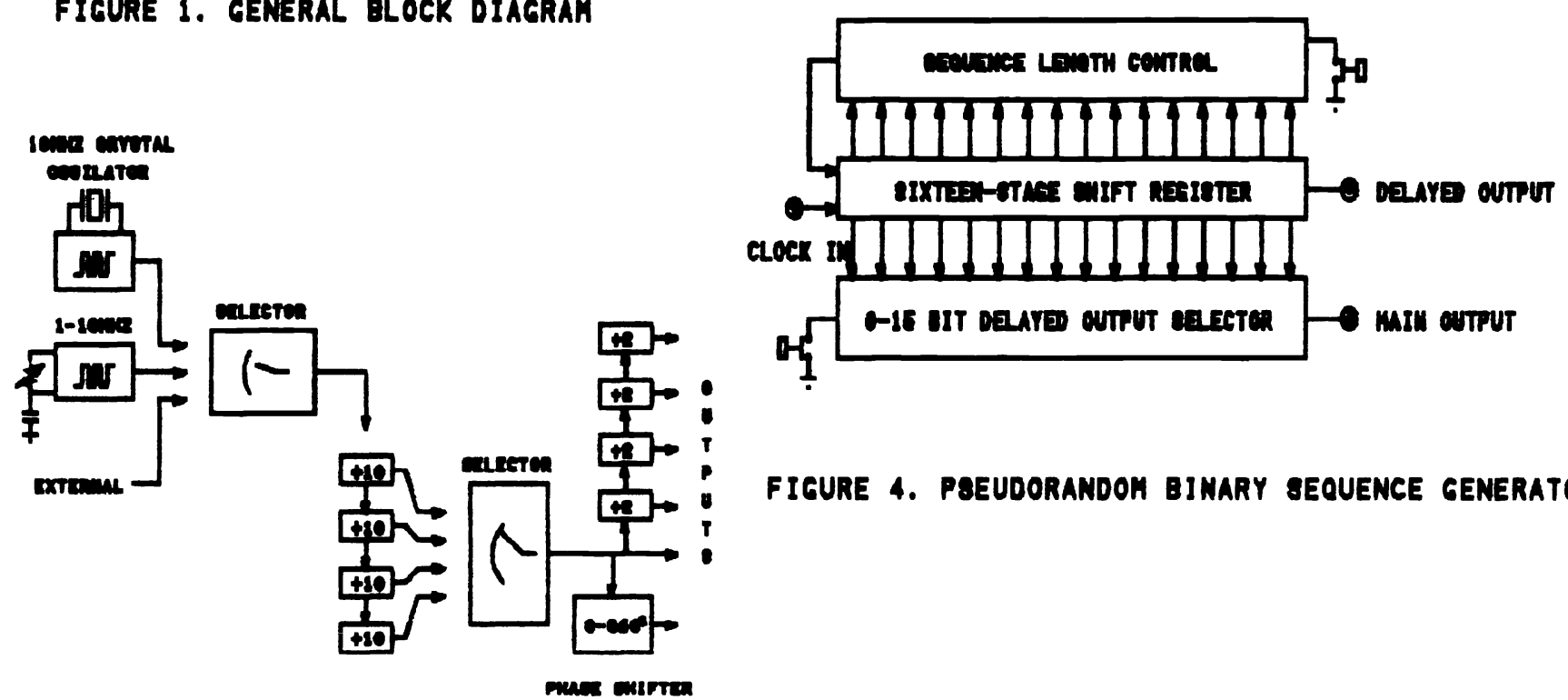

FIGURE a. MAOTER CLOCK GENERATOR
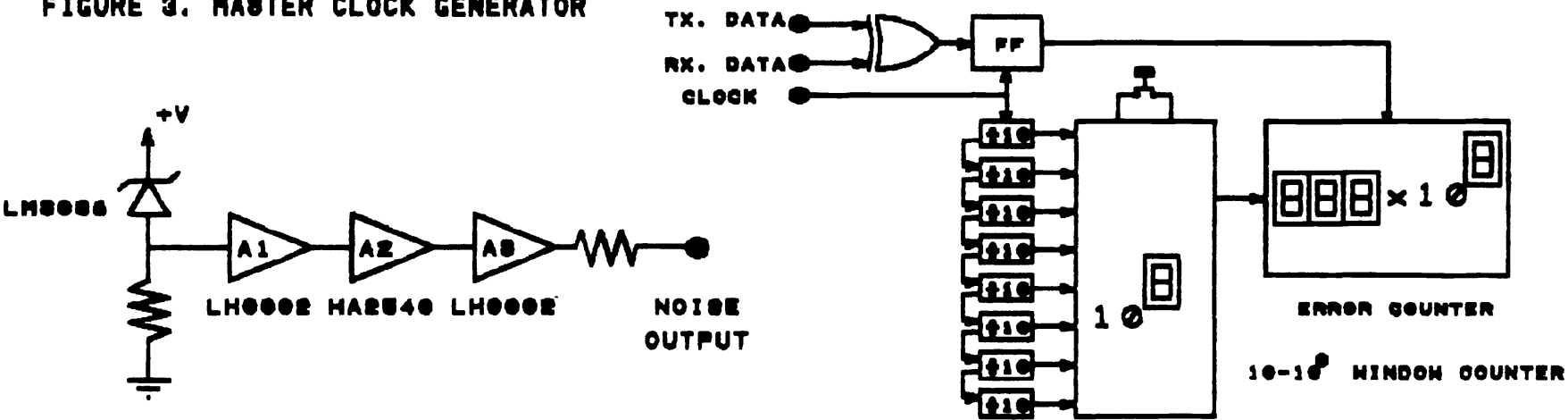

FIGURE 5. NOIBE GENERATOR

FIGURE 6. BIT ERROR RATE (BER) METER 


\section{OPTICAL TRANSHITTERS AND RECEIVERS}

So far digital data transmission has been the main application for fiber optics in telecommunications. Since one of the main constraints in our development is to build a low cost system, the light source chosen for the transmittcrs is a low power, low cfficicncy, infrarcd light (830 nm) cmittcr diode (IRED) from lotorola (LFOE71), which is part of a low cost family of components for fiber optic applications (FLCS - Fiber 0ptic Low Cost System ${ }^{4}$. Its maximum switching speed is $60 \mathrm{~ns}$ and its maximum continuons current is $60 \mathrm{~mA}$. For the recciver a PIN diodc (MFOD71) with a scnsitivity of $0.2 \mu \mathrm{A} / \mu \mathrm{W}$ and a response time of $5 \mathrm{~ns}$, which is spectrally matched to the source ${ }^{5}$, was chosen.

The digital transmittcr (scc Figurc 2) is formed by two TTL compatiblc buffers that drive a high speed transistor, which switches the IRED current. The maximum current may be adjusted between 5 and $90 \mathrm{~mA}$ with a variable resistor. The digitall receiver is formed by a PIN diode, followed by two wideband linear voltage amplifiers and a threshold comparator. In both, transmitter and receiver, there are several test points available for switching measurements and noise evaluation using a spectrum analyzer. The total system response time is 250ns, which allows for a binary transmission ratc of 4 Mbit/s. Faster responscs can be achicved improving the recciver circuit with faster and more expensive amplifiers.

Analog transmission is also possible and efficient through optical fiber, but nonlinear effects in transmission and reception must be carefully studied. The analog transmitter was build sensing the power supply current of a wideband linear amplifier with a IRED. The bias current of the amplifier also biases the IRED, and may be adjusted between 5 and 50 $\mathrm{mA}$. The receiver is also formed with a PIN diode followed by a tranconductance amplifier and two wideband amplifiers. The final 3dBbandwith available is $160 \mathrm{kHz}$, which may be improved using faster amplifiers.

\section{MASTER CLOCK GENERATOR}

Timing signals are needed to synchronize external equipment. This module (scc Figurc 3) provides two TTL compatiblc clock signals, onc of variablc frequency, between 1 and $10 \mathrm{MHz}$, and another fixed and stable (crystal controlled) at $10 \mathrm{MHz}$. From either one it is possible to obtain derived signals using a decimal divider of up to four decades and a binary divider with four taps. The minimum frequency is then $6.25 \mathrm{~Hz}$. Besides the original signal, a phase-shifted output it is also available to provide a timing signal for receiving purposes. 


\section{PSEUDO-RANDOI SEqUENCE GENERATOR}

This module provides a test signal usually used to evaluate the performance of digital transmission sytems with random sequences. In our case this signal is of the class known as maximum-length sequence ${ }^{6}$. which has certain optimum properties related to its autocorrelation function and its length. These sequences are generated using a (modulo-2)linear feedback shift register (see Figure 1) that adds up some pre-defined stages to the input. The sequence generated by an m-stage shift register is periodic with period $2^{\mathrm{m}}-1$, which is the longest sequence that can be generated. The autocorrelation function $R(k)$ is bi-valued: 1 for $k=0$ and $-1 /\left(2^{m}-1\right)$ everywhere else. In our development the sequence length is adjustable between $2^{2}-1$ and $2^{16}-1$. Two outputs are available, one delayed with respect. to the other by a programmable number of bits between 0 and 15 . In this development two programmable logic array (PLA) devices (PLS173 ${ }^{7}$ ) and a generic array logic (GAL16V8 ${ }^{8}$ ) circuit are used to reduce the board size.

\section{NOISE GENERATOR}

In order to evaluate the performance of a digital receiver it is necessary to have a continuous wideband noise source available. The statistical properties of this signal are also important, being the additive white gaussian noise the most widely used due to some no so obvious but well known information theory reasons?. In our development the noise source used is a reverse biased base-emitter junction (see Figure 5), working in the zener breakdown region ${ }^{10}$, followed by a wideband amplifier. The final noise $3 \mathrm{~dB}$-bandwith is $5 \mathrm{MHz}$ with an adjustable power between $40 \mathrm{dBm}$ and $-20 \mathrm{dBm}$.

\section{BER METER}

The performance of a digital communication system may be evaluated from end-to-end measuring the bit error rate at the receiver. Through this mcasurcments it is also possiblc to cvaluatc the signal to noisc (S/N) ratio at the receiver end, but a wide scale range is necessary since the probability of error decreases very fast with increasing $S / N$ ratio. This module (see Figure 6) has two da.ta imputs tha.t a.re synchronously compared with the leading or the trailing edge of an external clock. Differences are counted during a programmable window, between 1000 to $10^{8}$ clock cicles, and shown in a three-digit mantissa plus one-digit exponent display. This module is implemented with a programmable generic array logic (GAL20V8) device to reduce its final size.

\section{AKNOWLEDGIENTS}

This development has been performed with partial support from the Instituto Tecnológico de Elcctrónica y Tclccomunicacioncs (ITEC), a administrative unit from the Empresa Nacional de Telecomunicaciones (TELECOM), Bogotá, Colombia. 


\section{REFERENCES}

1. Edmund Scicntific Company, Barrington (USA).

2. Terry G. White, Fiber Optic Lab Manual, Industrial Fiber Optics, Scottsdale, Arizona, 1989.

3. P. Brack and A. Schappi, Fiberoptic Digital Transmission System, Swiss Federal Institutc of Tcchnology (ETH), Zurich, 1989.

4. Motorola Inc., Optoelectronics Devices Data, p. 5. 2, 1986.

5. Motorola Inc., Optoelectronics Devices Data, pp. 5. 2-5. 5, 1986.

6. John G. Proakis, Digital Communications, pp. 396-399, McGraw-Hill, 1989.

7. Signetics, Programmable Logic Data Manual, p. 5. 61, 1986.

8. Lattice Semiconductor Corporation, Generic Array Logic GAL16V8, Portland, 1988.

9. Simon Haykin, Digital Communications, pp. 13-11, John Wiley \& Sons, New York, 1988.

10. Paul R. Gray, Rober G. Meyer, Analysis and Design Of Analog Integrated Circuits, p. 613 John Wiley \& Sons, New York, 1981. 